- Highlights the introduction of a new type of sweet with a sour coating.

- Confirms the high erosive capacity of this type of confectionery.

- Highlights the fact that deciduous enamel is more prone to erosion than permanent enamel.

\title{
Sour sweets: a new type of erosive challenge?
}

\author{
R. Davies, ${ }^{1}$ L. Hunter, ${ }^{2}$ T. Loyn ${ }^{3}$ and J. Rees ${ }^{4}$
}

Objective To assess the erosive potential of a number of commercially available sour sweets in the laboratory.

Methods The erosive potential was assessed by measuring the $\mathrm{pH}$, neutralisable acidity and ability to erode permanent and deciduous enamel. These parameters were compared to those of an orange juice positive control.

Results The $\mathrm{pH}$ of the sour sweets ranged from 2.30-3.14 with their neutralisable acidity ranging from $9.78-66.9 \mathrm{ml}$ of $0.1 \mathrm{M} \mathrm{NaOH}$. The amount of permanent enamel removed following one hour immersion in the drinks ranged from 2.16-10.88 $\mu \mathrm{m}$ and from 1.02-18.34 $\mu \mathrm{m}$ for deciduous enamel. In comparison, the orange juice (Tropicana ${ }^{\mathrm{TM}}$ smooth) control had a pH of 3.86, a neutralisable acidity of $37.1 \mathrm{ml}$ of $0.1 \mathrm{M} \mathrm{NaOH}$ and removed $5.23 \mu \mathrm{m}$ of permanent enamel and $6.27 \mu \mathrm{m}$ of deciduous enamel.

Conclusion All the sour sweets tested were found to be erosive, some more so than orange juice. This information will be of use to clinicians when counseling younger patients with tooth surface loss.

\section{INTRODUCTION}

Dental erosion is defined as an irreversible loss of dental hard tissues due to a chemical process without the involvement of microorganisms. ${ }^{1}$ This process may be caused by extrinsic or intrinsic agents. Extrinsic agents include acidic foodstuffs, beverages, snacks and may also occur following environmental exposure to acidic agents. ${ }^{2,3}$ Intrinsic erosion is associated with gastric acid and may present intra-orally following vomiting, regurgitation, gastro-oesophageal reflux or rumination. ${ }^{4}$

The evidence linking tooth surface loss with diet is based on a number of case reports and a few epidemiological studies. Millward et al. ${ }^{5}$ examined 101 school children and found a high level of tooth surface loss associated with the consump-

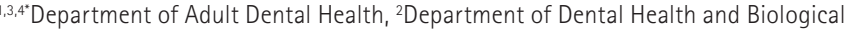
Sciences, School of Dentistry, Cardiff University, Heath Park, Cardiff, CF14 4XY ${ }^{*}$ Correspondence to: Professor Jeremy S. Rees

Email: reesjs1@cardiff.ac.uk
}

Online article number E3

Refereed Paper - accepted 12 July 2007

DOI: $10.1038 /$ bdj.2007.1203

${ }^{\circledR}$ British Dental Journal 2007; 204: E3 tion of soft drinks, particularly carbonated beverages. Jarvinen et $a l .{ }^{6}$ in a case-controlled study found that the risk for tooth surface loss was increased if citrus fruit was consumed more than twice daily or if sports drinks were consumed more than once a week.

In the 2003 national survey of children's dental health in the UK, ${ }^{7} 20 \%$ of five-year-olds were found to have evidence of tooth surface loss on the buccal surface of one or more maxillary primary incisors; tooth surface loss on the lingual surfaces of these teeth was more common, with over half of children of this age being affected. At age eight years, 4\% of children showed evidence of tooth surface loss on the buccal surface of one or more maxillary permanent incisors; by age 15 years, $14 \%$ of children were similarly affected. As in the analogous 1993 survey, ${ }^{8}$ tooth surface loss was more common on the lingual surface of the permanent maxillary incisors, 14\% of eight-year-olds and 33\% of 15-year-olds being affected. The proportion of first permanent molars with evidence of tooth surface loss on the occlusal surface rose with age (10\%, 19\% and $22 \%$ at age 8,12 and 15 respectively).

Over the last few years, sour sweets appear to have gained in popularity in the UK. The process for creating these products was developed in the late 1970s when Frank Galatolie, then a national sales manager with a confectionery distributor called Jaret, suggested the development of sour products in soft confectionery. Canadian manufacturing colleagues were encouraged to develop the candy by experimenting with regular gum based products through the addition of a sour flavoured coating applied to the surface of the sweet. A product called 'Sour Patch Kids' was introduced to the US market in 1985; this seems to be the first recorded sour sweet. ${ }^{9}$ The sour flavour is developed by the addition of organic acids, particularly lactic, citric and malic acids.

Although sour sweets are available in traditional lozenge shapes, many more have been designed as novelties, some even resembling toys. Concerningly, some are also designed to prolong contact with the oral hard and soft tissues.

The aim of this study was to compare a number of commercially available sour sweets with orange juice, the hypothesis being that the former would not be more erosive than the latter. 


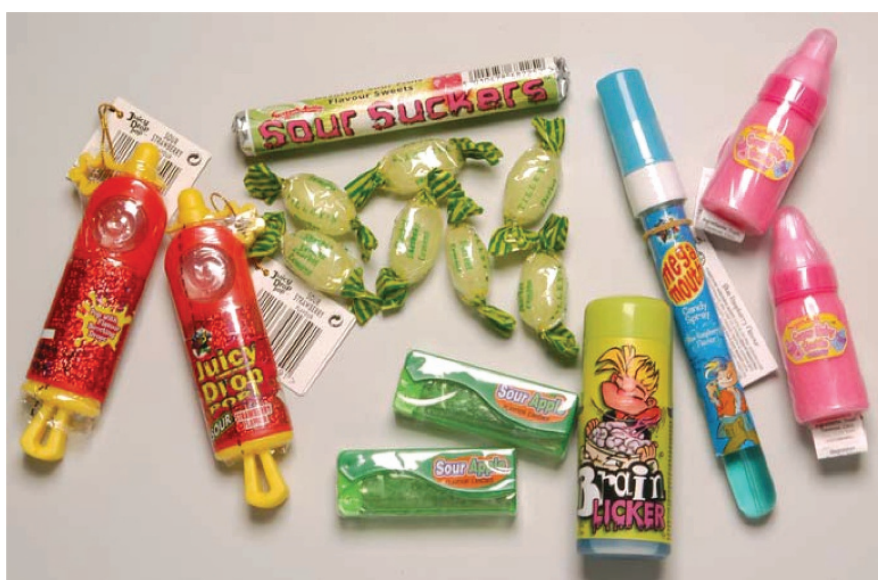

Fig. 1 The sour sweet products tested

Table 1 Sour sweet contents

\begin{tabular}{l|l}
\hline Product & Contents \\
\hline Brain Licker & Glucose, fructose, sugar, citric acid, malic acid, lactic acid \\
\hline Juicy Drop Pop & Glucose syrup, sugar, lactic acid, citric acid \\
\hline Mega Mouth & Glucose, citric acid \\
\hline Sherbet Lemons & Sherbet (bicarbonate of soda and tartaric acid) \\
\hline Sour Apple & Glucose syrup, sugar, lactic acid, citric acid \\
\hline Sour Sucker & Glucose syrup, sugar, lactic acid, citric acid \\
\hline Super Baby Bottle & Sugar, citric acid, malic acid
\end{tabular}

\section{MATERIALS AND METHODS}

Seven sour sweets were chosen for this study on the basis that they were widely available to the general public. The sour sweets and their ingredients, as stated on the manufacturers' labels, are shown in Figure 1 and the product contents are listed in Table 1. Unfortunately, the manufacturers do not state the amount of citric acid or other organic acids present in each product. Prior to testing, each sweet was broken up with a pestle and mortar and $10 \mathrm{~g}$ of the resultant powder was dissolved in $20 \mathrm{ml}$ of deionised water. The erosive potential of each sweet solution was then assessed by measuring $\mathrm{pH}$, neutralisable acidity and the ability to remove enamel in vitro.

$\mathrm{pH}$

The $\mathrm{pH}$ of each sour sweet was tested using an electronic $\mathrm{pH}$ meter (Model 701A, Orion Research Inc) at $37^{\circ} \mathrm{C}$ on a heated magnetic stirrer. The $\mathrm{pH}$ meter was calibrated using test solutions of known pH (Fisher Scientific International) before testing the sweets. Each sweet was tested using five different samples.

\section{Neutralisable acidity}

The neutralisable acidity of each sour sweet was tested by placing $20 \mathrm{ml}$ of the powdered sweet solution in a glass beaker within a thermostatically controlled water bath held at $37^{\circ} \mathrm{C}$. $0.1 \mathrm{M}$ sodium hydroxide solution was gradually added to the sample and the $\mathrm{pH}$ rise was continuously monitored until neutrality was reached. Each sample was stirred continuously as the solution of sodium hydroxide was added. The volume of sodium hydroxide required to increase the $\mathrm{pH}$ of the sample to neutrality was noted; this test was repeated five times for each sour sweet.

\section{Enamel erosion}

Measurements of enamel loss were made using profilometry according to the method of West. ${ }^{10}$ The source of the permanent enamel was extracted unerupted third molar teeth from individuals residing in a non-fluoridated area. Specimens of primary enamel were derived from recently extracted, caries-free primary canines. These were collected from children of either gender who were undergoing extraction for orthodontic treatment. At the time of extraction, donors were resident in areas where the water supplies contained less than $0.3 \mathrm{ppm}$ fluoride. Thus the level of fluoride incorporation into enamel was anticipated to be low, but was not further characterised. The specimens were sectioned longitudinally and embedded in a low exotherm epoxy resin (Stycast 1266, Emerson \& Cuming, Nijverheidsstraat, 2431 Westerlo, Belgium). The outer surfaces of the enamel samples were lightly ground with first 600-grit and then 1200-grit abrasive discs (Kemet International Ltd, Parkwood Trading Estate, Maidstone, Kent) to produce a flat surface. Three baseline readings using a profilometer (Planer Products Ltd, Sunbury on Thames, UK) were recorded for each enamel sample. Only samples with a stylus deflection of less than an average $\pm 0.30 \mu \mathrm{m}$ deflection were used in the study. The diamond stylus had a tip radius of $20 \mu \mathrm{m}$ with a head velocity of $10 \mathrm{~mm} / \mathrm{min}$. The force of the stylus varied linearly with deflection at a rate of $8 \mathrm{mg} / \mu \mathrm{m}$ up to a maximum of $1 \mathrm{~g}$ at $100 \mu \mathrm{m}$.

After baseline profiles were determined in triplicate, specimens were randomly allocated to one of eight treatment groups. The enamel samples were taped to expose a $2 \mathrm{~mm}$ width of enamel (approximate enamel area of $10 \mathrm{~mm}^{2}$ ). Individual enamel specimens were suspended in a glass beaker and exposed to $20 \mathrm{ml}$ of each sour sweet solution and stirred in a thermostatically controlled water bath at $37^{\circ} \mathrm{C}$ for one hour. Following exposure, the enamel specimens were rinsed in water, dried and the tapes removed. Surface enamel loss was measured on the profilometer in triplicate, with the amount of enamel loss recorded in micrometers. Means were calculated from triplicate measurements.

Five permanent and five deciduous enamel specimens were also immersed in Tropicana ${ }^{\mathrm{TM}}$ smooth brand orange juice (positive control) for one hour.

Statistical analysis of the results for $\mathrm{pH}$, neutralisable acidity and enamel erosion was carried out using analysis of variance followed by Tukey's test. The threshold for statistical significance was set at $\mathrm{p}<0.05$.

\section{RESULTS}

The results for the $\mathrm{pH}$ values are given in Table 2 . The $\mathrm{pH}$ of the sour sweets tested ranged from 2.30-3.14. These values show the sour sweets to be more acidic than the orange juice control ( $\mathrm{pH}$ 3.6). Brain Licker was statistically significantly more acidic ( $\mathrm{p}<0.001)$ than Juicy Drop Pop, Sherbet Lemon, Sour Apple, Sour Sucker and orange juice.

The results for the neutralisable acidity values are given in Table 2. These values ranged from $9.78 \mathrm{ml}$ for Sour Apple to $66.9 \mathrm{ml}$ for Juicy Drop Pop. The orange juice control had a neutralisable acidity value of $19.68 \mathrm{ml}$. Juicy Drop Pop had 
a neutralisable acidity value which was statistically significantly greater $(p<0.001)$ than that of the other sour products and the orange juice control. The neutralisable acidity values of the sour sweets were all statistically significantly greater than orange juice at the $\mathrm{p}<0.001$ level (Juicy Drop Pop, Mega Mouth, Sherbet Lemon, Sour Apple and Super Baby Bottle) or at the $\mathrm{p}<0.01$ level (Sour Sucker).

The amount of permanent and deciduous enamel lost following contact with the sour sweets is shown in Table 2. The amount of permanent enamel removed ranged from 2.16 to $10.88 \mu \mathrm{m}$. In comparison, the orange juice positive control produced a mean surface loss of $3.24 \mu \mathrm{m}$. Super Baby Bottle produced the greatest enamel loss at $10.88 \mu \mathrm{m}$ and this value was statistically significantly different from Brain Licker, Juicy Drop Pop and Sherbet Lemon at the $p<0.001$ level. It was also statistically significantly different from Mega Mouth and orange juice at the $\mathrm{p}<0.001$ level, but was not significantly different from Sour Sucker.

For deciduous enamel, the erosion vales ranged from 1.02$18.34 \mu \mathrm{m}$ and overall these enamel loss values were higher than the values for permanent enamel, apart from the product Juicy Drop Pop. The two most aggressive products, Super Baby Bottle and Sour Sucker, produced significantly more erosion than the orange juice positive control at the $\mathrm{p}<0.001$ level.

\section{DISCUSSION}

The aim of this study was to compare the erosive effects of a variety of sour sweets with orange juice. Although the $\mathrm{pH}$ of some commercially available products has been assessed previously, ${ }^{11}$ the neutralisable acidity and enamel erosion in vitro had not been assessed.

All the sour sweets were highly acidic, their initial $\mathrm{pH}$ values ranged from 2.30-3.14. The only sour sweet common to this work and the work of Beeley ${ }^{11}$ was Brain Licker. Beeley ${ }^{11}$ reported a $\mathrm{pH}$ of 1.7 , while the $\mathrm{pH}$ in this study was slightly less acidic at 2.3. These $\mathrm{pH}$ values are well below the known $\mathrm{pH}$ for the initiation of erosion, which is thought to be $4.5 .^{12}$ Furthermore, the very acidic $\mathrm{pH}$ of the sweets combined with prolonged oral contact must surely represent a risk of damage to both the lips and oral mucosa and the Food Standards Agency have issued a warning to this effect. ${ }^{13}$

It is also important to quantify the neutralisable acidity of a product when assessing its erosive potential. ${ }^{14}$ The neutralisable acidity of these sour sweets varied widely from 9.78-66.9 $\mathrm{ml}$ of sodium hydroxide and this wide variation is probably due to the differing levels of citric, lactic and malic acids in the various sweets. The lower neutralisable acidity values of less than $20 \mathrm{ml}$ of $0.1 \mathrm{M}$ sodium hydroxide are comparable to other products that have previously been tested such as alcopops, ${ }^{15,16}$ ciders $^{17}$ and white wines. ${ }^{18}$ However, the highest neutralisable acidity value of $66.9 \mathrm{ml}$ is the highest value reported in confectionery or food to the authors' knowledge. This is particularly worrying as this amount of freely available acid certainly represents a risk to the oral soft tissues as well as enamel and dentine.

A similar pattern was seen in respect of the enamel erosion values. The amount of enamel erosion produced by some of the products was of the order of 2-3 $\mu \mathrm{m}$ over one hour which is again similar to that produced by other foods and drinks. ${ }^{14-17}$ However, some of the products were producing 7-10 $\mu \mathrm{m}$ loss for permanent enamel which is again the highest value reported in confectionery or food to the authors' knowledge. The amount of deciduous enamel lost was, for most of the products tested, higher than seen with the permanent enamel. This was not particularly surprising as previous studies have found that deciduous enamel is more susceptible to erosion. ${ }^{19}$ For some of the products, the standard deviations for enamel erosion were quite wide and this probably reflects the natural biological variation in the structure of the enamel used.

What was more surprising was the values of the two most erosive products, Super Baby Bottle $(16.49 \mu \mathrm{m})$ and Sour Sucker $(18.34 \mu \mathrm{m})$. These again would seem to be the highest values reported in confectionery or food to the authors' knowledge and were statistically significantly higher than the orange juice control at the $\mathrm{p}<0.001$ level.

Previous studies have shown that in most instances the combination of an acidic $\mathrm{pH}$ with a high neutralisable acidity value results in high levels of erosion. This was certainly the case in this study for the products Sour Sucker and Super Baby Bottle that produced erosion values of 7-18 $\mu \mathrm{m}$. However, other products with similar $\mathrm{pH} /$ neutralisable acidity profiles, such as Brain Licker and Juicy Drop Pop, did not produce nearly as much enamel loss. The reason for this is not immediately obvious, but it may be that a particular combination of sugars confers some sort of protection or it may be that some of the sweets contained naturally occurring buffers. Alternatively, it may be a reflection of the adhesive properties of the sweet once dissolved in solution.

Table 2 Results for $\mathrm{pH}$, neutralisable acidity and enamel erosion (standard deviation in parentheses)

\begin{tabular}{l|l|l|l|l}
\hline Sour sweet & $\mathrm{pH}$ & Neutralisable acidity $(\mathrm{ml})$ & Permanent enamel erosion $(\mu \mathrm{m})$ & Deciduous enamel erosion $(\mu \mathrm{m})$ \\
\hline Brain Licker & $2.30(0.01)$ & $49.0(0.82)$ & $2.85(0.45)$ & $3.69(0.85)$ \\
\hline Juicy Drop Pop & $2.74(0.05)$ & $66.9(4.36)$ & $2.16(0.36)$ & $1.02(0.25)$ \\
\hline Mega Mouth & $2.40(0.06)$ & $45.3(0.40)$ & $5.57(2.62)$ & $8.35(2.21)$ \\
\hline Sherbet Lemons & $2.66(0.05)$ & $18.40(0.66)$ & $3.71(2.27)$ & $10.61(2.29)$ \\
\hline Sour Apple & $3.14(0.05)$ & $9.78(0.49)$ & $3.51(0.56)$ & $10.48(1.27)$ \\
\hline Sour Sucker & $2.66(0.08)$ & $31.8(1.17)$ & $7.84(3.23)$ & $18.34(3.30)$ \\
\hline Super Baby Bottle & $2.32(0.10)$ & $48.2(2.64)$ & $10.88(3.57)$ & $16.49(7.76)$ \\
\hline Tropicana ${ }^{\text {TM }}$ orange juice & $3.86(0.05)$ & $37.1(0.31)$ & $5.26(0.47)$ & $6.27(2.66)$
\end{tabular}


The erosion results of this in vitro study must also be interpreted with a certain degree of caution, as they will tend to over-estimate the amount of enamel lost compared to the clinical case. In the latter, the enamel surface will be covered by a protective pellicle and/or plaque layer and the tooth surface will also be subject to the flushing, buffering and remineralising effects of saliva. ${ }^{20,21}$ Indeed, Addy et al..$^{22}$ have suggested that the assessment of enamel erosion using in vitro profilometry over-estimates erosion by a factor of 10 due to the protective factors mentioned above. Furthermore, all of these sour sweets contain large amounts of organic acids to develop the characteristic sour flavour. These large amounts of acid will stimulate salivary flow once the sweets are introduced into the mouth and the flushing and buffering effects of the increased salivary flow will help counteract the erosive effects of these sweets.

The method for assessing enamel erosion may also be criticised, as the contact time between the enamel and sour sweet was one hour. However, many of these products, particularly the lollipops, seem to be designed to maximise the contact time between the product and the oral tissues, therefore contact times of an hour, or even more, may be more realistic than initial examination of the method would suggest.

All the sour sweets contained simple carbohydrates, principally as glucose syrup. This also poses an increased cariogenic challenge in addition to the erosive challenge. This would suggest that one is likely to see caries superimposed on erosive lesions and anecdotally the authors are diagnosing dentinal caries where the enamel seems to have been lost due to erosion.

In spite of these obvious shortcomings, this study has shown that sour sweets are potentially erosive. The authors accept that some of this erosive potential may well be countered by the increased salivary flow engendered, but the only way to test this effect is with a clinical study. In conclusion, this information will be of use to clinicians when counselling patients who are diagnosed with tooth surface loss and who use sour sweets on a regular basis.

1. Eccles J D. Tooth surface loss from abrasion, attrition and erosion. Dent Update 1982; 35: 373-381.

2. Eccles J D, Jenkins W G. Dental erosion and diet. J Dent 1974; 2: 153-159.

3. Asher C, Read M J F. Early enamel erosion in children associated with the excessive consumption of citric acid. Br Dent J 1987: 162: 384-387.

4. Järvinen V K, Rytömaa I, Heinonen O P. Risk factors in dental erosion. J Dent Res
1991; 70: 942-947.

5. Millward A, Shaw L, Smith A J, Rippin J W, Harrington E. The distribution and severity of tooth wear and the relationship between erosion and dietary constituents in a group of children. Int J Paediatr Dent 1994; 4: 151-156.

6. Shaw L, Smith A J. Erosion in children: an increasing clinical problem? Dent Update 1994; 21: 103-106.

7. Lader D, Chadwick B, Chestnutt I et al. Children's dental health in the United Kingdom, 2003. London: Office of National Statistics, 2005.

8. O'Brien M. Children's dental health in the United Kingdom, 1993. London: HMSO, 1994.

9. Cadbury Schweppes. Sour Patch Kids webpage. www.cadburyschweppes.com/ EN/Brands/About/Confectionery/factsheet sourpatch.htm. Accessed 26.1.06.

10. West N X, Maxwell A, Hughes J A, Parker D M, Newcombe R G, Addy M. A method to measure clinical erosion: the effect of orange juice consumption on erosion of enamel. J Dent 1998; 26: 329-335.

11. Beeley J A. Novelty sweets: a new cause of erosion? British Society for Dental Research Annual Meeting, Dundee, 2005. Abstract No. 194.

12. Mclntyre J M. Erosion. Aust Prosthodont J 1992; 6: 17-25.

13. Food Standards Agency. Brain Licker novelty sweet warning. 12 May 2003. www. food.gov.uk/news/newsarchive/2003/may/brainlicker. Accessed 26.1.06.

14. Rees J S. The role of drinks in erosion. Dent Update 2004; 31: 318-326.

15. Rees J S, Burford K, Loyn T. The erosive potential of alcoholic lemonades. Eur J Prosthodont Restor Dent 1999; 6: 161-164.

16. Rees J S, Davis F J C. An in vitro assessment of the erosive potential of some designer drinks. Eur J Prosthodont Restor Dent 2001; 8: 149-152.

17. Rees J S, Griffiths J. An in vitro assessment of the erosive potential of conventional and white ciders. Eur J Prosthodont Restor Dent 2002; 10: 167-171.

18. Rees J S, Hughes J, Innes C. An in vitro assessment of the erosive potential of some white wines. Eur J Prosthodont Restor Dent 2002; 10: 37-42.

19. Hunter M L, West N X, Hughes J A, Newcombe R G, Addy M. Relative susceptibility of deciduous and permanent dental hard tissues to erosion by a low $\mathrm{pH}$ fruit drink in vitro. J Dent 2000; 28: 265-270.

20. Woltgens J H M, de Blick-Hogervorst J M A, Bervoets D J. Enamel erosion and saliva. Clin Prev Dent 1985; 7: 8-10.

21. Hay D I, Pinsent B R W, Schram C J, Wagg B J. The protective effect of calcium and phosphate ions against acid erosion of dental enamel and dentine. BrDent J 1962: 112: 283-287.

22. Hughes J A, West N X, Parker D M, Newcombe R G, Addy M. Development and evaluation of a low erosive blackcurrant juice drink in vitro and in situ. 1. Comparison with orange juice. J Dent 1999; 27: 285-289.

\section{MANUFACTURERS' DETAILS}

Brain Licker: King Regal, Barcelona, Spain

Juicy Drop Pop: Topps Co. Inc, 401 York Avenue,

Duryea, PA 18642, USA

Mega Mouth: Candy Warehouse, 5314 Third St,

Irwindale, CA 91706, USA

Sherbet Lemons: Tilley's, Bedfordshire, UK

Sour Apple: A Quarter Of Ltd, 565 Dutton Way,

Shadsworth Business Park, Lancashire, UK

Sour Sucker: A Quarter Of Ltd, 565 Dutton Way,

Shadsworth Business Park, Lancashire, UK

Super Baby Bottle: Sweetie Bag Ltd, 25 Hampshire Terrace,

Portsmouth, Hampshire, UK

Tropicana UK Ltd, PO Box 6642, Leicester, LE4 8WZ 